\title{
Neuroepidemiology Increases Impact Factor
}

\author{
Gustavo C. Román
}

This last issue of 2003 brings excellent news to the readers, editorial board, and publishers of Neuroepidemiology. According to the Institute for Scientific Information (ISI), Neuroepidemiology increased its impact factor (IF) to 2.139 in 2002 from 1.390 in 2001. This culminates an upward 5-year trend that reflects the increasing quality of the work submitted for publication in this journal.

The IF is considered a putative marker of journal quality [1]. A creation of Eugene Garfield, the founder of ISI, the IF was described in 1972 as a ratio between citations and citable items published in a particular period [2]. The numerator for this ratio is the number of all current year (2002) citations in the literature; the denominator is the number of citable items, i.e., articles published in the journal during the preceding two years $(2000,2001)$. Large-volume publications and review journals have the highest IFs, but from thousands of journals only a minority achieve an IF $>3.0$ [3].

Despite persistent [4] and sometimes vociferous criticisms of its role [5], the IF is associated with higher methodological quality of clinical research articles [6], often reflecting higher rejection rates. The latter are a measure of the quality control exerted by peer reviewers, deputy editors, and members of the editorial board. In the final analysis, this increase of Neuroepidemiology's IF reflects the coming of age of this young discipline, with ramifications to all clinical subspecialties of neurology.

\section{Changes in the Editorial Board}

With sadness, I announce the passing of a member of our editorial board, Prof. M. Mongi Ben Hamida, director of the National Institute of Neurology La Rabta in Tunis,
Tunisia. An illustrious neurologist from La Salpêtrière school, Prof. Ben Hamida described a number of muscular and genetic neurological disorders peculiar to North Africa; he was past-president of the Pan African Association of Neurological Sciences (PAANS), former mayor of the city of Kelibia, and organizer of neurology training in Tunisia. Along with his family, friends, and numerous disciples, we will miss him deeply.

I would like to extend my warmest welcome to the editorial board to Prof. Michel Dumas, founder and director of the Institute of Neuroepidemiology and Tropical Neurology, University of Limoges, France, and one of the most productive researchers in the field. Over the years, Prof. Dumas and his team have been responsible for the neuroepidemiology education and neurology training of most of the neurologists currently teaching and serving French-speaking Africa, as well as a growing number of Latin American countries. We are delighted and honored by Prof. Dumas' acceptance to serve in the editorial board of Neuroepidemiology.

\section{References}

1 Saha S, Saint S, Christakis DA: Impact factor: A valid measure of journal quality? J Med Libr Assoc 2003;91:42-46.

2 Garfield E: Citation analysis as a tool in journal evaluation. Science 1972; 178:471-479.

3 Garfield E: How can impact factors be improved? BMJ 1996;313:411413

4 Opthof T: Sense and nonsense about the impact factor. Cardiovasc Res 1997;33:1-7.

5 Hecht F, Hecht BK, Sandberg AA: The journal 'impact factor': A misnamed, misleading, misused measure. Cancer Genet Cytogenet 1998;104: $77-81$.

6 Lee KP, Schotland M, Bacchetti P, Bero LA: Association of journal quality indicators with methodological quality of clinical research articles. JAMA 2002;287:2805-2808

\begin{tabular}{ll}
\hline KARGER & ( ) 2003 S. Karger AG, Basel \\
Fax +41 61 306 1234 34 & \\
$\begin{array}{l}\text { E-Mail karger@karger.ch } \\
\text { www. karger.com }\end{array}$ & $\begin{array}{l}\text { Accessible online at: } \\
\text { www.karger.com/ned }\end{array}$
\end{tabular}

Gustavo C. Román

PO Box 29486

San Antonio, TX 78229 (USA)

Tel +1 2106175161, Fax +1 2105674659

E-Mail romang@uthscsa.edu 